The thirty chapters follow closely the arrangement of a standard text-book of organic chemistry. Methods of formation are followed by a review of reactions of the type of compound under discussion. The Grignard and Friedel-Crafts reactions, and the diene synthesis, with their exceptionally wide applications, are treated separately. In general, however, reactions are classified under the heading of compounds of the type with which they are chiefly associated : thus, the Fries reaction will be found under the heading of phenol esters; and the Wagner, Nametkin and Demjanow rearrangements under alicyclic hydrocarbons.

The work is a useful compendium of an enormous amount of material, and is fully documented, although the literature of the past decade is sometimes sparsely represented. Theoretical discussions are not included, and reaction mechanisms are mentioned only when generally accepted. The text, formulæ and tables are clearly printed by a modern economic process; nevertheless, the price is distinctly high. As might be expected, in so extensive a compilation, misprints are not uncommon.

Dr. Migrdichian, who is senior research chemist to the American Cyanamid Co., with a record of some thirty years in the field of work leading to these volumes, is to be congratulated upon the result of prolonged labours that will minimize those of the many organic chemists who will derive welcome help from this publication.

JOHN READ

\section{ELECTRICITY AND ELECTRICAL MACHINES}

\section{Electrical Engineering (General)}

Electrical Circuits-Instruments and Measurements -Electric and Magnetic Fields-Conductors-Insulating and Magnetic Materials-Electronic Tubes. By A. T. Dover, Dr. F. T. Chapman, Prof. F. Brailsford and Harley Carter. (Electrical Engineering Series.) Pp. ix +489. (London and New York: Longmans, Green and Co., Ltd., 1956.) 50s. net.

\section{Electrical Machines}

By A. Draper. (Electrical Engineering Series.) Pp. xvi +346 . (London and New York: Longmans, Green and Co., Ltd., 1956.) 40s. net.

The General Theory of Electrical Machines

By Bernard Adkins. Pp. ix + 236. (London : Chapman and Hall, Ltd., 1957.) 45s. net.

\footnotetext{
$7 \mathrm{HE}$ first two books belong to a series intended for use by students preparing for Higher National Certificate, degree, and other examinations. The preface states that "Electrical Engineering (General)", the first of the series, is limited in scope to theory connected with electric circuits, instruments and materials for use with direct currents and alternating currents of power frequencies. The manner and depth of treatment vary considerably from topic to topic. Three chapters contributed by Prof. Brailsford provide a lucid and up-to-date account of ferromagnetic phenomena. Unfortunately, the same fundamental approach has not been applied to the discussion of conducting and insulating materials, the treatment of which is reminiscent of an engineer's handbook. This criticism could also be levelled at some of the material concerning commercial measuring instrumenta. It is perhaps inevitable that a book written
}

by a penel of authors should consist of discrete sections, but it must be confusing to students to find, for example, a discussion of network theorems as part of direct-current circuit theory, without any mention of their general application, while later the star-delta equivalent impedances of a 3-phase circuit are derived without any reference to an earlier and similar derivation among the network theorems. Despite the declared limitation to power frequencies, two chapters on electronics describe various types of radio-frequency apparatus. A useful and comprehensive selection of examples, with answers, many taken from examination papers, is provided at the end of the book.

"Electrical Machines' has been written as a textbook for students and not as a treatise for designers." Here, at last, students can find under one cover details of nearly all types of electrical machines. The omission of the single-phase machine is, however, to be regretted ; it is, after all, very common. Academically there also appears to be no justification for including the mercury-are rectifier in a book on machines. The approach to the subject is logical and on traditionsl lines, and should appeal to the student of electronics studying machines as a secondary subject. He will also find the sections on rotating and magnetic amplifiers very useful. The book can be recommended unconditionally to such students. Those taking heavy-current subjects for a degree course will probably wish for greater depth of treatment, but it is an excellent second-year book. The author and the British Thomson-Houston Co., Ltd., are to be highly commended for the clarity of the diagrams, so essential to a book on machines. The examples at the end of the book are well chosen, even though there is a mixture of units. The appendix on the measurement of three-phase power will prove very useful to students in the laboratory.

The general theory of electrical machines has been presented by several writers in a form so mathematical as to appear remote from whirling masses of copper and iron, and the publication of Mr. Adkins's book, in which the theory is applied to computing the details of machine performance under varying conditions, is all the more welcome. The author is a reader in the University of London, and his careful explanation of small detail shows his appreciation of the needs of students; but he has behind him an industrial career much longer and more distinguished than most professors or lecturers. This greatly enhances the value of his work, for he speaks with authority on the relative numerical importance of the terms in his equations, and is thereby enabled, by eliminating small effects, to present a clearer picture of the chief phenomens. His use of the 'per-unit' system is perhaps open to criticism in a students' book; it is essy to see its value to the designer, but it takes the student too far from fundamentals, destroys the dimensional consistency of the equations, and involves the author in quite a number of interpolated explanations of the values of coefficients. It is also possible to regret the somewhat disproportionate space accorded to the synchronous machine as compared with other types of a.c. motor. Nevertheless, the book is the best yet written in English to develop machine performance from general principles in a manner calculated to appeal to engineers and engineering students.

T. Wrison

D. A. JoNes

G. W. Carter 